\title{
PROVINHA BRASIL E SUAS POSSIBILIDADES NO PLANEJAMENTO DOCENTE: REFLEXÕES DE PROFESSORES DE UMA ESCOLA PÚBLICA MUNICIPAL DA REGIÃO SUDOESTE DO PARANÁ
}

\section{PROVINHA BRASIL AND ITS POSSIBILITIES IN THE TEACHING PLANNING: TEACHERS REFLECTIONS OF A MUNICIPAL PUBLIC SCHOOL FROM SOUTHWEST REGION OF PARANÁ}

Elisane Daló Tibes ${ }^{1}$

Maria Josélia Zanlorenzi ${ }^{2}$

\section{RESUMO:}

O presente artigo trata-se de um Trabalho de Conclusão de Curso (TCC), desenvolvido no Curso de Pedagogia da Universidade Estadual do Centro-Oeste UNICENTRO/GuarapuavaPR realizado no ano letivo de 2017. Tivemos como objetivo dessa pesquisa analisar as possibilidades de utilizar os resultados da Provinha Brasil como diagnóstico de planejamento escolar. Bem como entender os impactos que a utilização desses resultados causam ao currículo. Este trabalho foi elaborado com base em estudos bibliográficos e documentais, sendo utilizados artigos e dissertações de mestrado que contemplam a discussão em torno da problemática. Utilizou-se, também, a Lei de Diretrizes e Bases da Educação 9394/96, as Diretrizes Curriculares Nacionais da Educação Básica e Soares (2009). Através da investigação foi possível observar que o uso dos resultados dessa avaliação na elaboração do planejamento escolar e do professor, leva ao engessamento do currículo e a classificação dos alunos.

PALAVRAS-CHAVE: Políticas Educacionais; Avaliação em Larga Escala; Provinha Brasil; Planejamento Escolar.

\begin{abstract}
:
The current article is a completion of course work developed in the course of Pedagogy of the Universidade Estadual do Centro-Oeste UNICENTRO/Guarapuava-PR accomplished in the academic year of 2017. We had how objective of this research analyze the possibilities of use the results of Provinha Brasil as diagnostic of school planning. As well as understand the impacts that the use of this results cause to the curriculum. This work was elaborate with base in bibliographical and documentary studies, being used articles and Masters dissertations that contemplate the discussion around the problematic. It was used too, the Law of Guidelines and Bases of Education 9394/96, the National Curricular Guidelines for Basic Education and Soares (2009). Through of investigation was possible observe that use the results of this evaluation in the elaboration of school and teacher planning, takes to the plastering of curriculum and students classification.
\end{abstract}

KEYWORDS: Educational Policies; evaluation on large scale; Provinha Brasil; School Planning.

\footnotetext{
${ }^{1}$ Pedagoga pela Universidade Estadual do Centro-Oeste do Paraná - UNICENTRO - Campus Guarapuava-PR

${ }_{2}^{2}$ Professora no Departamento de Pedagogia da Universidade Estadual do Centro-Oeste - UNICENTRO - Campus Guarapuava-PR, , Mestre em Educação Pela UEPG, Doutora em Educação pela UNESP - FCT Presidete Prudente-SP
} 


\section{INTRODUÇÃO}

O interesse pela temática Provinha Brasil como diagnóstico de Planejamento surge da necessidade de entender como é avaliada a Educação Básica. Para isso, primeiramente faz-se necessário compreender as avaliações em larga escala existentes no país e para que servem, dentre estas elegeu-se a Provinha Brasil para uma análise mais detalhada de seus objetivos e concepções, para assim entender como é possível utilizá-la como diagnóstico de planejamento.

A Provinha Brasil é um instrumento de avaliação que oferece um diagnóstico do nível de Alfabetização e Letramento dos anos iniciais do Ensino Fundamental, entretanto essa avaliação segue o padrão das demais avaliações em larga escala, sendo aplicada de forma padronizada a todas as escolas públicas do Brasil. Com essa pesquisa buscamos compreender de que forma os resultados dessas avaliações, mais precisamente a Provinha Brasil, são incorporados ao planejamento escolar e os impactos que a incorporação desses resultados causam no currículo e, consequentemente no processo de ensino aprendizagem escolar.

Essa pesquisa foi realizada com base em estudos de artigos e teses já publicados com a temática das avaliações em larga escala e o planejamento escolar e a pesquisa de campo foi desenvolvida com professores dos Anos Iniciais do Ensino Fundamental em uma escola municipal na região sudoeste do Estado do Paraná.

No presente estudo, temos o objetivo de responder a seguinte pergunta, "A Provinha Brasil serve como diagnóstico para o planejamento escolar?”. O artigo está assim dividido: "Avaliação; Refletindo sobre o conceito", traz uma reflexão sobre os conceitos de avaliação e sobre as avaliações em larga escala que são aplicadas na Educação Básica, as origens, objetivos e porque são realizadas atualmente; "Planejamento escolar: sua importância e relação com resultado da Provinha Brasil"; nesse item discutimos sobre o conceito e a importância do planejamento e sua relação com os resultados da Provinha Brasil. "O aproveitamento do resultado da Provinha Brasil na elaboração do planejamento na percepção de professores e gestores de uma escola municipal" momento em que é feita a análise das entrevistas com os professores dos Anos Iniciais do Ensino de Nove Anos de uma escola municipal e o confronto com os objetivos da Provinha Brasil.

A partir das leituras pode-se dizer que avaliações como a Provinha Brasil, formuladas a distância sem considerar o cotidiano escolar, desconsiderando as particularidades e os contextos sociais e culturais, produzem a classificação e a segregação dos sujeitos que possuem um rendimento menor. 


\section{AVALIAÇÃO: REFLETINDO SOBRE O CONCEITO}

Avaliar é uma prática comum em nosso dia a dia, em tudo o que fazemos. $\mathrm{Na}$ escola não é diferente. A avaliação faz parte do cotidiano de professores e alunos. Esse processo tem muitas finalidades, no caso da escola é um processo que busca avaliar os conhecimentos adquiridos pelos alunos durante o período escolar e a qualidade da educação. Para o educador avaliar requer investigar o desempenho do educando buscando melhorar seu aprendizado e consequentemente seu desempenho. De acordo com Luckesi (2011 p. 184):

Quando se pratica algum tipo de avaliação, não se busca a classificação de alguma coisa, mas sim o seu diagnóstico que pode apontar para a necessidade de novos cuidados com uma ação em andamento.

$\mathrm{O}$ ato de avaliar é amplo, não se restringe ao único objetivo de medir os conhecimentos adquiridos. Avaliar não deve ser sinônimo de punir ou classificar os alunos, não se deve usar da avaliação para selecionar os melhores. A avaliação deve ser utilizada como parte do processo do conhecimento, investigando o que o aluno sabe e o que pode ser melhorado, ou que metodologias podem ser adotadas para melhorar o aprendizado dos alunos. Essa avaliação deve levar em conta todo o contexto escolar, social e econômico em que o aluno se encontra, para que o professor possa planejar suas ações para atingir os objetivos.

Existem diferentes formas de avaliação no contexto escolar. A avaliação formativa ocorre durante todo o processo de ensino aprendizagem, faz um diagnóstico das potencialidades do aluno, procura detectar os problemas e buscar a intervenção imediata para sanar as dificuldades apresentadas pelos alunos. A avaliação contínua é feita por meio da observação dos registros das atividades feitas pelos alunos. Constitui instrumento indispensável para o professor na busca do sucesso escolar dos alunos "[...] a avaliação formativa pode ser entendida como uma prática de avaliação contínua que objetiva desenvolver as aprendizagens" (CASEIRO e GEBRAN, 2008, p. 143).

Tanto a Lei de Diretrizes e Bases da Educação Nacional 9394/96 (LDB) como as Diretrizes Curriculares Nacionais da Educação Básica (DCNs) defendem que a avaliação deve ser processo e não fim. A avaliação deve levar em conta o cotidiano da sala de aula e a vida dos alunos, basear-se na qualidade do aprendizado dos alunos e não na quantidade. A LDB 9394/96 em seu artigo 24 inciso $5^{\circ}$, orienta, que a escola, ao avaliar o aluno deve primar pela: "Avaliação contínua e cumulativa do desempenho do aluno, com prevalência dos aspectos qualitativos sobre os quantitativos e dos resultados ao longo do período sobre os de eventuais provas finais".

Nas Diretrizes Curriculares Nacionais da Educação Básica DCNs da Educação 
Básica a avaliação deve assumir caráter processual, formativo e participativo, ser contínua, cumulativa e diagnóstica e parte integrante do currículo. Realizada pelo professor e pela escola, é redimensionadora da ação pedagógica e exige o uso de diferentes formas de avaliar o aluno. Na prática pedagógica, as DCNs da Educação Básica orienta:

Utilizar vários instrumentos e procedimentos, tais como a observação, o registro descritivo e reflexivo, os trabalhos individuais e coletivos, os portfólios, exercícios, provas, questionários, dentre outros, tendo em conta a sua adequação à faixa etária e às características de desenvolvimento do educando (BRASIL, 2013, p.138).

Nas avaliações realizadas pelos alunos o fator qualitativo deve prevalecer sobre os quantitativos, pois o processo de aprendizado tem que ser respeitado, sendo que alguns alunos demoram mais que outros para aprender e, há que se respeitar esse tempo do aluno.

\section{A avaliação em larga escala no contexto educacional brasileiro}

As avaliações em larga escala tal qual como são conhecidas e aplicadas hoje, fazem parte das políticas públicas educacionais que se originaram entre as décadas de 1980 e 1990, quando o Brasil passava por um processo de redemocratização.

Após sair de um período de ditadura, o país necessitava de uma reforma administrativa. Chirinéa (2010, p.33), destaca que o Estado sai de um "[...]modelo burocrático para um modelo gerencial e descentralizado[...]”, passando a dividir as responsabilidades com outras instituições não estatais e instituições privadas que prestam serviços sociais, como saúde, educação e seguridade social. Assim o Estado não deixa de subsidiar os serviços, ele reduz seu papel de executor dos serviços e aumenta o controle das instituições que oferecem esses serviços.

O Estado passa de executor para controlador dos serviços, minimizando suas funções nas questões sociais. A reforma do Estado foi implantada com objetivo de racionalizar os recursos investidos e diminuir sua interferência nas políticas sociais. A implantação dessa reforma teve influência das políticas internacionais, com ideário neoliberal que buscava dividir responsabilidades com a sociedade civil. "O neoliberalismo pressupõe que o Estado deve intervir o mínimo possível nas questões econômicas, políticas e sociais, transferindo essa responsabilidade para o mercado" (CHIRINÉA, 2010 p. 26). Ainda de acordo com a ideologia neoliberal, somente o mercado é capaz de estruturar e ordenar de forma racional os serviços sociais a serem ofertados. Desse modo foi implantado um modelo administrativo que busca a eficiência, a qualidade e a produtividade dos serviços públicos, ou seja, é implantado um modelo de mercado. 
No campo educacional o Estado não é mais o provedor, agora passa a ser o regulador da educação. A educação, por ser entendida como um serviço social, sofreu impactos com a reforma administrativa do Estado. Com essa configuração de Estado Regulador a interferência na educação se dá "principalmente pelo controle de conteúdo curriculares, pela avaliação externa e pelo estímulo à competição entre as escolas e sistemas de ensino" (CHIRINÉA, 2010, p.36). O currículo passa a ser usado como instrumento de controle, as avaliações em larga escala passam a ser implantadas massivamente na educação e seus resultados divulgados e utilizados para estimular o rankeamento e a competição entre as escolas.

Na década de 1980 a educação no Brasil passava por um momento caótico, poucas crianças em idade escolar tinham acesso à escola. Havia muitas repetições na primeira série, os professores não tinham formação específica e somando-se a isso, a maioria da população vivia abaixo da linha da pobreza ${ }^{3}$. Foi diante desse quadro social e educacional que foram implantadas as reformas na área da educação. A justificativa para essas reformas foi a necessidade de modernizar e universalizar os sistemas de ensino, as reformas buscaram reordenar a educação de acordo com as políticas implantadas e a ordem econômica vigente.

Porém, não bastava somente garantir o acesso à educação, necessitava-se garantir a permanência dos alunos nas escolas, assim para modernizar a educação o Ministério da Educação (MEC) recorre a empréstimos com o Banco Mundial com a finalidade de modernizar os sistemas de ensino, garantir o acesso da população às escolas e melhorar seu desempenho. Cabe ressaltar que esses empréstimos estavam condicionados a "[...] a esforços planejados pelos governos estaduais à correção da situação, buscando eficiência e eficácia do sistema" (CHIRINÉA, 2010, p. 42). A lógica de mercado direciona as reformas educacionais financiadas pelo Banco Mundial, com o modelo gerencial e os conceitos de eficácia e eficiência.

Assim na busca por ferramentas que aferissem a qualidade da educação ofertada surgem as avaliações em larga escala, utilizadas como indutoras da qualidade da educação. Diante disso o currículo passa a ser direcionado "para uma educação a qual pode e deve ser medida, avaliada e conclusa para resultados". (BORDIN, 2015, p.83). A avaliação passa a ser instrumento para a indução da qualidade da educação ofertada.

Já que o Estado não é mais o provedor, agora é o regulador, “a educação passa a ser direcionada para modelos padronizados, tendo como finalidade a eficiência e a qualidade,

\footnotetext{
3 Para a Organização das Nações Unidas ONU e o Banco Mundial extrema pobreza é aquela em que a pessoa vive com menos de US\$ 1,25, disponível em http://mundoeducacao.bol.uol.com.br/geografia/a-pobreza-no-brasil.htl; acesso em 08 ago. 2017.
} 
muito em voga nos discursos dos financiadores do conhecimento" (BORDIN, 2015, p.82). Nessas avaliações denominadas em larga escala "o desempenho dos alunos foi considerado como uma das dimensões da qualidade do ensino" (HORTA NETO, 2007, p.6). Assim com interesse no financiamento educacional dos organismos internacionais "[...] a avaliação em larga escala, passou a se constituir em um instrumento de controle do trabalho escolar e de fortalecimento da meritocracia" (SOUZA, 2014. P. 413).

Na ânsia de criar políticas que buscassem o desenvolvimento econômico e social do país, pela lei 10.172 de janeiro de 2001, foi promulgado o Plano Nacional de Educação (PNE) para o decênio 2001-2011 e por meio deste, determina-se as metas e estratégias para a educação no prazo de dez anos. Esse plano foi elaborado com participação popular, associações e entidades de educadores e anuncia a importância dos sistemas de avaliação. Em seu conteúdo, define a avaliação como: "[...] prioridade associada ao desenvolvimento de sistemas de informação e de avaliação em todos os níveis e modalidades de ensino [...]" (WERLE, 2011, p.778),

Buscando aperfeiçoar e aprimorar o processo de coleta e divulgação de dados aprimorando a gestão e a melhoria do ensino foi instituído também o Movimento Todos Pela Educação, com a participação da sociedade, iniciativa privada, organizações sociais, educadores e gestores, com o objetivo de assegurar a todas as crianças e jovens o direito a educação básica de qualidade. A partir de então foram elaboradas propostas com vistas a garantir uma Educação Básica de qualidade a todos os brasileiros até o ano de 2022. O PNE prevê que até o ano de 2022 sejam alcançadas as seguintes metas:

1) Toda criança e jovem de 4 a 17 anos estará na escola; 2) Até 2010, 80\% e, até 2022, 100\% das crianças de 8 anos de idade estarão plenamente alfabetizadas; 3 ) Todo aluno aprenderá o que é apropriado para a sua série; 4) Todo aluno concluirá o Ensino Fundamental até os 16 anos de idade e o Ensino Médio até os 19 anos; 5) O investimento em educação deve ser garantido e gerido de forma eficiente e ética. (WERLE, 2011, p.782).

O Movimento Todos Pela Educação está atrelado a criação do Índice de Desenvolvimento da Educação Básica (IDEB) e lança a Provinha Brasil com o objetivo de avaliar a alfabetização inicial dos alunos no $2^{\circ}$ ano. Buscando os resultados dos investimentos feitos na educação, monitorando o sistema educacional, intervindo financeiramente para que a educação possa atingir a meta idealizada.

O Plano Nacional de Educação 2014-2024, aprovado pela Lei no 13.005, de 25 de junho de 2014, é elaborado em um contexto em que o discurso sobre a qualidade da educação 
está ligada aos resultados das avaliações em larga escala. A Meta 7, por exemplo, fortalece o IDEB e propõe que os resultados do SAEB e da Prova Brasil sejam os determinantes da qualidade da educação, essa Meta também define que a média a ser atingida seja de 6,0 nos anos iniciais do ensino fundamental (BRASIL, 2014).

A Educação Básica é avaliada pelo Sistema de Avaliação da Educação Básica (SAEB) que é coordenado pelo (INEP) Instituto Nacional de Estudos e Pesquisas Educacionais Anísio Teixeira que por sua vez é uma autarquia federal vinculada ao Ministério da Educação (MEC). O Sistema de Avaliação da Educação Básica (SAEB) instituído pela portaria $\mathrm{n}^{\circ} 1.795$ de 27 de dezembro de 1994, avalia os conhecimentos nas áreas de Língua Portuguesa e Matemática de alunos do $5^{\circ}$ e $9^{\circ}$ ano da Educação Básica e dos alunos do $3^{\circ}$ ano do Ensino Médio. Para Souza (2014) essa é a primeira iniciativa nacional de responsabilidade do executivo federal caracterizada por avaliação de proficiências por amostragem das redes de ensino realizadas em cada unidade da federação que busca conhecer e coletar dados referentes a qualidade da educação.

O SAEB avalia a qualidade do ensino e da educação por meio de testes de desempenho aplicado a uma representativa amostra de alunos; são: “[...]procedimentos padronizados de construção dos instrumentos de medida, levantamento e processamento de dados, o que o inscreve na categoria da avaliação em larga escala” (COTTA, 2001, p.92).

Entre as avaliações da Educação Básica destacam-se a Prova Brasil, Avaliação Nacional de Alfabetização (ANA), a Provinha Brasil e o Exame Nacional do Ensino Médio (ENEM). A Avaliação Nacional do Rendimento Escolar, conhecida como Prova Brasil, é de caráter censitário e aplicada a alunos do $5^{\circ}$ e $9^{\circ}$ ano. Também avalia os conhecimentos nas áreas de Língua Portuguesa - com foco na leitura e Matemática - com foco na resolução de problemas. Souza, (2014) descreve que o objetivo da referida avaliação é auxiliar os governantes no direcionamento dos recursos técnicos e financeiros, estabelecendo metas e implantando metas e ações pedagógicas e administrativas para a melhoria da qualidade do ensino ofertado, seus resultados são utilizados no cálculo do IDEB.

Sobre Avaliação Nacional de Alfabetização (ANA), de acordo com o Portal INEP, a Avaliação Nacional da Alfabetização (ANA) é mais uma das avaliações externas aplicadas na Educação Básica. Com o objetivo de avaliar os níveis de alfabetização e letramento dos alunos do $3^{\circ}$ ano do Ensino Fundamental, essa avaliação prioriza a Língua Portuguesa com ênfase na leitura, escrita e matemática, fornecendo resultados de desempenho de leitura e escrita e desempenho em matemática. 
A Provinha Brasil, de acordo com o Portal INEP, é descrita como uma avaliação diagnóstica, aplicada a alunos do $2^{\circ}$ ano do Ensino Fundamental. Composta por testes de Língua Portuguesa e Matemática que visam diagnosticar os problemas iniciais na questão da alfabetização é realizada duas vezes ao ano, uma no início e outra no final do ano letivo. Essa avaliação é de adesão voluntária e seus resultados não são utilizados para compor os índices do IDEB.

Analisando a descrição dessas avaliações podemos observar que todas elas tratam de avaliações que priorizam a Língua Portuguesa com ênfase na leitura e Matemática com foco na resolução de problemas. Nota-se que há uma espécie de hierarquização desses conteúdos em relação aos demais. Essa regulação dos conteúdos, provoca um engessamento dos mesmos e leva as escolas a priorizar o que é exigido nas avaliações em detrimento de outros.

Em relação ao ENEM cabe destacar que:

Criado em 1998, é um exame individual, de caráter voluntário, oferecido anualmente aos estudantes que estão concluindo ou que já concluíram o ensino médio em anos anteriores. Seu objetivo principal é possibilitar uma referência para auto avaliação, a partir das competências e habilidades que estruturam o Exame (PERONI, 2009, p.291)

O Exame Nacional do Ensino Médio ENEM diferente das demais avaliações, é composto por provas interdisciplinares, porém essa avaliação é de caráter individual e não faz um diagnóstico dos problemas vivenciados pelo estudante durante sua passagem pelo Ensino Médio.

Essa avaliação não mede a capacidade do aluno acumular ou assimilar informações. Esse caráter individual proposto por essa avaliação atribui somente ao aluno a responsabilidade pelo fracasso ou sucesso da educação, deixando de avaliar os fatores internos e externos, como o nível social e econômico e as condições dos estabelecimentos de ensino, que interferem na educação, como se o fracasso ou sucesso não tivesse nada a ver com a qualidade da educação ofertada. Assim como as demais avaliações o ENEM, tende a "[...]a prejudicar os alunos oriundos de escolas que contam com precárias condições de funcionamento, oferecidas pelo poder público, que, tradicionalmente, atendem à população pobre" (SOUZA, 2003, p. 182).

Para aprimorar a percepção, em 2007 o INEP cria o Índice de Desenvolvimento de Qualidade da Educação Básica/IDEB, aplicado em todo o país e se destina a avaliar o desenvolvimento escolar, de acordo com Wiebusch (2011), O IDEB é a combinação de dois 
indicadores: Fluxo escolar, ou seja, a promoção, repetência e evasão dos alunos coletadas através do Censo Escolar, e o desempenho nas avaliações externas - SAEB e Prova Brasil. A meta para o ano de 2021 é que o IDEB de todas as escolas seja 6,0, mesma média dos países desenvolvidos.

Para se fazer o cálculo do IDEB de uma escola calcula-se o resultado obtido pelos alunos nas avaliações em larga escala, Prova Brasil e SAEB, e a taxa de aprovação dos alunos da escola. Considerando assim somente os fins da educação e não o processo percorrido, nem suas particularidades. Dessa forma a educação passa a ser direcionada para a busca de um indicador considerado ideal. Para que a escola tenha seu desempenho avaliado pelo IDEB, é necessário realizar a Prova Brasil, sem a realização da mesma a escola não terá indicador de desempenho, demonstrando assim o incentivo a competição entre escolas e a imposição na questão da realização da Prova Brasil. Para Cária e Oliveira (2015, p.30):

IDEB foi apropriado pelas políticas públicas, não apenas como estratégia para conhecer a eficácia do trabalho educativo desenvolvido na escola e pela escola, mas passando a ser utilizado também como instrumento de poder sobre as escolas, seus atores e os gestores públicos, utilizando o resultado da avaliação em larga escala como critério de distribuição de recursos, públicos, aos entes federados [...].

Constata-se que o IDEB não funciona somente para acompanhar a qualidade da educação, é utilizado também como instrumento de poder, regulando assim as práticas educativas para alcançar melhores resultados nas avaliações e, consequentemente obter recursos econômicos. Incentiva a competitividade entre as escolas e o direcionamento do currículo para atender o que é pedido nas avaliações. Em decorrência do atual sistema de avaliação, é possível observar o efeito do IDEB nas escolas, o currículo é direcionado valorizando a leitura e a matemática e, “[...] Como somente essas áreas são utilizadas para se chegar ao IDEB, as escolas e os sistemas municipais e estaduais tendem a dar-lhes maior importância, em detrimento das outras [...]” (RONCA, 2013, p.82)

Diante da ideologia neoliberal e com a influência do Banco Mundial na educação, fica clara a implementação de políticas educacionais que interessam ao mercado internacional e que produza somente força de trabalho para esse mercado. As avaliações funcionam como um mecanismo de controle do Estado, pois vincula o rendimento dos alunos a uma espécie de bônus financeiro (CHIRINÉA, 2010, p.15)

Não se pode creditar somente as Avaliações Externas a capacidade de fazer o diagnóstico da qualidade da educação, pois nem sempre o conceito de qualidade é o mesmo para todas as escolas. A qualidade da educação é um fator complexo, depende de fatores in- 
ternos e externos da escola como por exemplo a infraestrutura e manutenção escolar, a formação continuada dos docentes, o respeito a diversidade escolar, ambiente escolar seguro, espaço adaptado para alunos com necessidades especiais, laboratório de informática e biblioteca com acervo acessível aos alunos, além da desigualdade social (CHIRINÉA, 2010, p.72)

Dessa forma a avaliação "perde seu caráter de diagnóstico de situações a serem aperfeiçoadas, para tornar-se instrumento de controle do Estado”. (SOUZA, 2009, p 20). Vinculado o rendimento dos alunos nas avaliações a um bônus financeiro para as escolas que atingirem níveis considerados satisfatórios, a qualidade não é mais vista como um direito, mas sim como uma exigência do mercado. Com o passar dos anos foram criados planos, metas, novas avaliações, mas não houve investimentos significativos na estrutura das escolas para

que a educação ofertada fosse mesmo de qualidade. É possível observar que as políticas educacionais com influência neoliberal, buscaram regular o currículo e incentivar o rankeamento e a competição entre as escolas.

\section{PROVINHA BRASIL: INTENÇÕES LEGAIS E REAIS}

A Provinha Brasil começou a ser aplicada no Brasil em 2008, atendendo a proposta incluída no "Compromisso Todos Pela Educação" referente a "alfabetizar as crianças até, no máximo, os oito anos de idade, aferindo os resultados por exame periódico específico" (WERLE, 2011, p. 787). Tem caráter censitário, aplicada a cada dois anos com alunos do $2^{\circ}$ ano dos Anos Iniciais do Ensino Fundamental nas escolas públicas da rede municipal, estadual e federal.

A Provinha Brasil avalia os conhecimentos de Língua Portuguesa com foco na alfabetização. Seu resultado oferece um diagnóstico do nível de Alfabetização e Letramento dos Anos Iniciais do Ensino Fundamental e indica as principais dificuldades dos alunos referentes a capacidade da produção escrita e da leitura. Busca identificar os avanços e limitações da alfabetização dos alunos, "oferecendo informações aos professores, gestores escolares, para acompanhar, avaliar, melhorar a qualidade da alfabetização e do letramento inicial” (WIEBUSCH, 2011, p. 64-65).

Pela Portaria Normativa No 10, de 24 de abril de 2007, o MEC institui a Provinha Brasil como avaliação da alfabetização inicial e apresenta os seguintes objetivos para a realização da mesma:

a) avaliar o nível de alfabetização dos educandos nos anos iniciais do ensino fundamental; b) oferecer às redes de ensino um resultado da qualidade do ensino, prevenindo o diagnóstico tardio das dificuldades de aprendizagem; c) concorrer para 
a melhoria da qualidade de ensino e redução das desigualdades, em consonância com as metas e políticas estabelecidas pelas diretrizes da educação nacional. (BRASIL, 2007).

Representa um dos indicadores da qualidade da educação e seu principal objetivo, além de avaliar o nível de alfabetização dos alunos é também utilizar os resultados para orientar e aprimorar as práticas pedagógicas visando a melhoria da alfabetização.

Desta forma, segundo o MEC, a Provinha Brasil pretende avaliar a qualidade das escolas e o nível de alfabetização dos municípios. É uma iniciativa que busca conhecer os problemas do sistema educacional e orientar as políticas públicas governamentais voltadas para sanar as deficiências e melhorar a qualidade do ensino.

A Provinha Brasil busca avaliar não somente a aprendizagem dos alunos, mas oferecer ao professor a oportunidade de avaliar sua conduta diante das necessidades que cada aluno apresenta. Com os resultados obtidos é possível redirecionar programas de formação continuada para os professores que atuam na alfabetização a fim de que possam melhorar ou modificar suas práticas pedagógicas para solucionar os problemas encontrados, contribuindo assim para o aprendizado efetivo dos alunos.

A Provinha Brasil é uma avaliação que nasce com o objetivo de fazer um diagnóstico da alfabetização inicial em alunos do $2^{\circ}$ ano do Ensino Fundamental nas escolas públicas, são testes padronizados que buscam medir o conhecimento dos alunos em escalas de proficiências. Os testes são utilizados para comparar os níveis alcançados e os conhecimentos adquiridos pelos alunos no início e no final do ano letivo.

Segundo as Diretrizes Curriculares Nacionais da Educação Básica, a ênfase dada às avaliações em larga escala “[...] pode produzir a inversão das referências para o trabalho pedagógico, o qual tende a abandonar as propostas curriculares e orientar-se apenas pelo que é avaliado por esses sistemas" (BRASIL, 2013 p. 124). Levando assim a um reducionismo do ensino aprendizagem, ao direcionar o que é ensinado para atender o que é pedido nessas avaliações. Isso faz com que a avaliação passe a não ser vista como parte do currículo.

Esse excesso de preocupação com os resultados dessas avaliações comprometem o aprendizado de outras áreas do ensino, uma vez que esses testes apesentam:

[...] pouca capacidade para realizar o diagnóstico a que se propõe, já que se distancia do cotidiano escolar e não pode captar sua tensões, possibilidades e, sobretudo, os conhecimentos, culturas e processos que partilham os estudantes entre si e com os docentes (ESTEBAN e WOLF, 2015,s/p). 
Quando se fala em avaliação em larga escala a expressão "padronização" chama bastante atenção. Esse tipo de avaliação, composto por testes padronizados, a exemplo da Provinha Brasil, ao se avaliar diferentes sujeitos com testes padronizados desconsidera a realidade de cada participante do processo e fortalece o caráter classificatório da avaliação dos sujeitos (ESTEBAN, 2012, p.584).

Essas avaliações formuladas a distância, sem considerar o cotidiano escolar, desconsiderando as particularidades e os contextos sociais e culturais, produzem a classificação e a segregação dos sujeitos que possuem um rendimento menor. Estimulando assim a separação e a comparação entre aqueles que alcançam um maior rendimento, com os que alcançam um rendimento ou nível inferior ao considerado adequado.

\section{PLANEJAMENTO E DA PROVINHA BRASIL NO CONTEXTO ESCOLAR}

Planejamento é um instrumento que orienta toda a ação educativa, construindo o processo de tomada de decisões sobre as ações. Não deve ser feito em um único dia, mas deve ser construído a cada dia e de acordo com a realidade educacional. O processo de planejar abrange experiências que professor e educando vivenciam, não ficando restrito somente aos conteúdos e métodos trabalhado na escola.

O planejamento é a racionalização, coordenação e organização de toda a ação docente. Deve articular as atividades escolares com o contexto social em que o aluno está inserido, é uma forma de direcionar o olhar para a realidade da escola.

É necessário que o planejamento assuma um caráter participativo e estratégico no espaço escolar, que não tenha sentido somente para a escola, mas para toda a comunidade integrada, em que o objetivo seja garantir a aprendizagem dos alunos.

Segundo Lopes (2014), em determinados momentos da história da educação brasileira, o planejamento era feito sem as devidas preocupações com as práticas metodológicas. Planejar resumia-se apenas a registro de atividades que o professor desenvolveria em sala de aula em um caderno ou fichas “[...] que, uma vez elaborados, serviriam por anos e anos, sendo retomados cada vez que o professor ia trabalhar o mesmo conteúdo" (LOPES, 2014, p.25). Podendo assim o professor passar por turmas diferentes e ensinar o mesmo conteúdo utilizando as mesmas práticas, ou mesmo um professor copiar o que o colega fez quando trabalhou aquele conteúdo, dessa forma planejar era “[...] estabelecer um roteiro que se aplicasse a qualquer realidade, por isso era aproveitado por anos a fio, pois o conhecimento era dado como pronto, acabado[...]" (MESQUITA E COELHO, 2008, p. $165)$. 
Ainda de acordo com Lopes, (2014) nos anos sessenta o planejamento surge como a solução para a falta de produtividade da educação, sendo o planejamento o instrumento que faltava para a educação avançar. Entretanto, para esse avanço o planejamento não levava em conta “[...] os fatores sociais, políticos e econômicos, dando-se muita ênfase ao aspecto academicista" (LOPES, 2014, p.25). Diante desse tecnicismo, o planejamento passou a ser elaborado por especialistas, “[...] o professor é afastado desse processo e recebe pronto o script para conduzir as atividades em sala de aula[...]" (MESQUITA E COELHO, 2008 p.173). O que estava proposto no planejamento de ensino não condizia com a prática do professor em sala de aula, levando a um controle externo da educação e a desvalorização do professor, que passou a ser um mero executor de um planejamento já feito por especialistas.

Nos anos 1990, através das reformas educacionais, foi introduzida uma nova concepção de planejamento escolar o Planejamento no Gerenciamento da Qualidade Total, "quando a Qualidade Total se expande no setor educacional, a escola passa a ser considerada uma empresa prestadora de serviços, e os alunos a sua clientela" (MESQUITA E COELHO, 2008, p. 172), baseados nos ideais neoliberais, assim a qualidade da educação passa a ser controlada por mecanismos de avaliação padronizada e o planejamento é direcionado para atender o mercado. A avaliação nessa nova forma de tecnicismo se dá através de modelos prédeterminados e padronizados, "as questões prontas e objetivas voltam ao cenário escolar" (MESQUITA E COELHO, 2008, p. 172), apontando mais uma vez o caráter classificatório em detrimento da aprendizagem dos alunos.

$\mathrm{O}$ ato de planejar deve fazer parte da rotina das escolas e dos educadores "[...] mas sem perder de vista o novo, estimulando a curiosidade e a participação, procurando envolver todos e sempre inovando nos velhos conteúdos" (LOPES, 2014, p.25) redimensionando a prática educativa a fim de manter o aluno interessado e colaborando com as ideias fazendo com que o aluno se sinta parte de processo educacional.

O planejamento deve ser pensado de acordo com a realidade da escola e dos educandos, porem a realidade não é estática, daí a necessidade de planejar, replanejar e reorganizar os conteúdos, as metodologias e as práticas pedagógicas. Não existe uma receita pronta sobre o planejamento o que existe é a necessidade de se adequar esse planejamento para que esse assegure o desenvolvimento e que sirva de norte às práticas em sala de aula, pois “[...] Um saber somente importa ser ensinado quando instiga o aluno a uma associação ao mundo que vive a realidade com a qual convive e os saberes que já acumulou" (LOPES, 2014, p.29). Para alcançar esse objetivo, o uso do planejamento é essencial. 
Para a elaboração e realização de um planejamento adequado, que desenvolva o aluno em todas suas potencialidades, há que se superar a visão autoritária e tecnicista do planejamento. Deve-se planejar de acordo com a realidade escolar e dos educandos a quem se propõe ensinar. Cabe a escola e ao professor planejar as ações e executa-las, por meio de situações de interação do aluno com o conhecimento.

A escola sofre influência direta do contexto em que está inserida e atende particularidades de uma realidade específica. É constituída por alunos de diferentes comunidades que trazem consigo cultura, costumes específicos, assim é preciso que a escola possua um planejamento que atenda as especificidades dos alunos e respeite seus anseios; um planejamento que aborde esses diferentes costumes e culturas.

Planejar e avaliar são dois instrumentos pedagógicos que auxiliam na prática educativa. A avaliação contribui para a estruturação do planejamento, pois os resultados da avaliação permitem que o planejamento seja organizado e reorganizado de forma que atenda às necessidades da escola e dos alunos. Através da avaliação que se torna possível compreender a eficácia ou não do planejamento.

Vemos hoje na escola, a busca pela qualidade da educação, as políticas educacionais são pensadas e propostas de forma que atendam essa busca. Assim a qualidade da educação é "medida" pelos resultados das avaliações em larga escala. Avaliações essas que já vêm prontas para que a escola aplique aos alunos e seus resultados servem de indicadores de qualidade. De acordo com o INEP, os resultados da Provinha Brasil fornecem informações sobre a alfabetização inicial e objetiva:

[...] o estabelecimento de metas pedagógicas para a rede de ensino; planejamento de cursos de formação continuada para os professores; investimento em medidas que garantam melhor aprendizado; desenvolvimento de ações imediatas para a correção de possíveis distorções verificadas; melhoria da qualidade e redução da desigualdade de ensino (BRASIL, 2017).

Aplicada aos alunos das escolas públicas de todo o Brasil, seus resultados orientam a prática pedagógica dos professores visando corrigir as possíveis distorções. Os resultados podem ser incorporados no planejamento dos professores para que conheçam as fragilidades e as corrijam, evitando assim problemas futuros na alfabetização.

No entanto, as avaliações em larga escala aplicadas na escola:

[...] não permite a explicitação/observação das diferenças em relação ao conteúdo do pensamento como também à maneira de pensar, uma vez que toda resposta diferente da predefinida representa um erro e a questão não é sequer marcada na Ficha de correção da Provinha Brasil (ESTEBAN, 2014, p. 474) 
Desfaz-se assim todo o discurso sobre o planejamento participativo, pois em uma mesma sala de aula existem diferenças, sejam socioeconômicas, ou de ritmos de aprendizagem. Ao se propor uma avaliação igual para todos, sem levar em conta os contextos em que se incluem, escola e alunos, é desfazer o discurso de que um planejamento só é relevante quando leva em consideração os sujeitos envolvidos. Não há como se pensar um planejamento e uma forma única de avaliar ou planejar as atividades desenvolvidas, pois o aluno da escola pública não é homogêneo, então não tem como propor que os caminhos para uma aprendizagem significativa sejam os mesmos. Bonamino e Sousa (2012) descrevem a preocupação com a relação entre o currículo e as avaliações em larga escala:

Discutem-se os riscos de as provas padronizadas, com avaliações que referenciam políticas de responsabilização envolvendo consequências fracas e fortes, exacerbarem a preocupação de diretores e professores com a preparação para os testes e para as atividades por estes abordadas, levando a um estreitamento do currículo escolar (2012, p. 373).

Há uma preocupação das autoras e, essa preocupação também é vista em sala de aula. Quando o foco das avaliações e consequentemente do planejamento estão desvinculados da sala de aula e o que é ensinado, reduz-se ao treinamento para o que é exigido na Provinha Brasil, para medir a qualidade da educação, ocorre uma descaracterização dos objetivos da Provinha Brasil e do próprio currículo da escola. Como pontuam as Diretrizes Curriculares Nacionais para a Educação Básica: “[...]a avaliação deixa de ser parte do desenvolvimento do currículo, passando a ocupar um lugar indevido no processo educacional. Isso ocasiona outras consequências, como a redução do ensino à aprendizagem daquilo que é exigido nos testes" (BRASIL, 2013, p. 124).

Durante a pesquisa notou-se a preocupação de se elaborar e aplicar um planejamento participativo que proporcione a oportunidade do aluno se desenvolver em todas as suas potencialidades, que relacionar o planejamento as avaliações mais especificamente a Provinha Brasil, não condiz com a concepção de um planejamento participativo, pois há um reducionismo do que é ensinado, e um controle através de testes prontos, não levando em conta a realidade e os conhecimentos que os alunos trazem consigo, nem a capacidade do professor de elaborar uma avaliação ou um planejamento.

\section{O APROVEITAMENTO DO RESULTADO DA PROVINHA BRASIL NA ELABORAÇÃO DO PLANEJAMENTO NA PERCEPÇÃO DE PROFESSORES E GESTORES DE UMA ESCOLA MUNICIPAL}


Antes de apresentar os dados faz-se necessário apresentar os indivíduos que participaram das entrevistas. As entrevistas seguiram um roteiro pré-estabelecido com perguntas semiestruturadas, com o objetivo de entender como os resultados da Provinha Brasil servem de diagnóstico para o planejamento escolar. Foram entrevistadas duas coordenadoras pedagógicas denominadas no decorrer do texto de Coordenara $\mathrm{C} 1$ e coordenadora C2; duas professoras alfabetizadoras, docentes no $2^{\circ}$ Ano do ensino fundamental, que estão atuando esse ano na escola, identificadas aqui de PA 1 e PA 2; e três professoras que atuaram no $2^{\circ}$ ano em 2016, denominadas de P1; P2; P3. Quanto ao gênero, todas são mulheres; a forma de vínculo com a escola, todas são concursadas. Em relação a formação das mesmas, todas são formadas em Pedagogia com especialização em diversas áreas da Educação e todas tem experiência com a alfabetização.

Quanto às características da escola e do município, o município hoje tem aproximadamente 7.000 habitantes, localizado na região sudoeste do Paraná. É um município de economia agrícola e conta com a exploração de uma usina hidrelétrica. A escola é a única do município, localizada na área urbana, atende os Anos Iniciais do ensino Fundamental, tem aproximadamente 470 alunos matriculados do $1^{\circ}$ ao $5^{\circ}$ ano do ensino fundamental. Os alunos são, em sua maioria, vindos da área rural do município, dos mais diferentes níveis sociais e econômicos. Quanto ao IDEB em 2015 a escola obteve nota 6,2.

A escola encontra-se em excelente estado de conservação, conta com 16 salas de aula, entre $1^{\circ}$ e $5^{\circ}$ Ano, atende nos períodos da manhã e tarde, todas as turmas de $1^{\circ}$ ano e turmas que possuem alunos inclusos contam com uma auxiliar. Faz parte da estrutura física da escola, uma sala de informática com acesso à internet, uma Sala de Recurso Multifuncional com materiais adaptados; uma sala de Reforço Escolar; quadra poliesportiva coberta; uma cozinha industrial; biblioteca com amplo acervo disponível para professores e alunos. O quadro docente é formado por 45 professores, desses, somente duas professoras não possuem graduação. Conta ainda com secretária, diretora e três coordenadoras pedagógicas e os alunos de $4^{\circ}$ e $5^{\circ}$ ano podem optar se querem estudar em tempo integral.

As entrevistas aconteceram nas dependências da escola, com o seguinte roteiro: Qual sua concepção sobre a Provinha Brasil? Como você percebe o planejamento escolar e sua execução pela escola e na sala de aula? Sobre a Provinha Brasil, como você percebe a contribuição desta avaliação na elaboração do Planejamento escolar? Comente sobre as possibilidades de utilizar o resultado da Provinha Brasil no Planejamento escolar e do professor. As perguntas foram elaboradas com a intenção de descobrir o que professoras e coordenadoras conhecem da Provinha Brasil e como os resultados dessa avaliação são 
utilizados no planejamento escolar.

As professoras em suas falas iniciais colocaram a questão da palavra prova, pois na escola são feitas avaliações no decorrer do ano letivo sem utilizar a palavra "prova" que essa palavra causa espanto e desconforto ao aluno. Nas palavras das professoras, um aluno ter que responder 20 questões sozinho, com outra pessoa observando, acaba por influenciar no resultado final da avaliação.

Sobre a Provinha Brasil as professoras sabem se tratar de uma avaliação adotada pela Secretaria de Educação, aplicada duas vezes no ano. O resultado serviria para orientar as práticas pedagógicas das mesmas, e que através dos resultados elas poderiam adequar suas metodologias para atender as dificuldades apresentadas pelos alunos. As professoras salientam que o discurso é interessante, mas que na prática não é assim que funciona. Consideram que a Provinha traz os conteúdos reduzidos, não abrangendo tudo o que é ensinado pela professora e ainda questiona "só porque em uma questão da Provinha o aluno não consegue identificar determinado gênero textual, não significa que ele não está alfabetizado?”.

Ao serem questionadas a respeito do que conhecem da Provinha Brasil, tanto as coordenadoras quanto as professoras demonstraram saber que se trata de uma avaliação que pretende fazer um diagnóstico de como está a alfabetização inicial dos alunos do $2^{\circ}$ ano. Colocaram também que veem a Provinha como um treino para avaliações como a Avaliação Nacional da Alfabetização ANA e a Prova Brasil, conhecem os objetivos e intenções da Provinha, mas questionam esses objetivos, pois na concepção dos professores essa avaliação é classificatória e não leva em conta a realidade escolar e dos alunos.

Quando questionadas sobre o planejamento escolar e sua execução na escola e na sala de aula, as coordenadoras falaram que o planejamento e o replanejamento é feito em conjunto. No planejamento diário, sempre que possível as professoras fazem junto, não ficam presas ao material didático e tem autonomia para elaborar atividades diferenciadas para os alunos que possuem dificuldades ou um ritmo mais lento de aprendizado. As coordenadoras fazem acompanhamento das atividades desenvolvidas pelas professoras, ainda destacam o fato de serem feitas sondagens periódicas com as turmas para acompanhar a evolução da aprendizagem dos alunos e acompanhar o trabalho das professoras. Nas palavras da coordenadora que aqui chamo de coordenadora 02:

"Não tiramos a autonomia do professor em sala de aula, mas fazemos o acompanhamento periódico do que está sendo ensinados e avaliamos se o planejamento precisa ser modificado para atender as necessidades dos alunos" 
(COORDENADORA 02).

As professoras, ao falarem sobre o planejamento, destacam a autonomia em sala de aula. Para elaborar as atividades de forma que atendam às necessidades e respeitem o ritmo de aprendizado dos alunos, as professoras destacam a questão do acompanhamento diário da evolução ou não dos alunos e a importância das atividades adaptadas aos alunos com mais dificuldades. Apesar das atividades serem diferenciadas, todos aprendem o mesmo conteúdo. Ainda a respeito do planejamento, as professoras comentaram sobre a importância de elaborar o planejamento e o replanejamento juntas, pois além de melhorar o trabalho, elas trocam experiências, metodologias e elaboram estratégias para melhorar o aprendizado dos alunos.

A respeito de como elas percebem a contribuição da Provinha Brasil na elaboração do planejamento escolar, todas falaram que não veem contribuição dessa avaliação, já que o planejamento da escola é participativo e os alunos tem a oportunidade de fazer investigações sobre o que é ensinado. As professoras e coordenadoras tem conhecimento que um dos objetivos da Provinha é fazer um diagnóstico da alfabetização para prevenir o diagnóstico tardio de dificuldades na alfabetização. Sabem também que é possível utilizar os resultados da avaliação para intervenções pedagógicas buscando à melhoria da qualidade do processo de ensino-aprendizagem, mas destacam que não utilizam por considerarem que a avaliação não leva em conta as particularidades dos alunos, já que a avaliação é a mesma para todos os alunos do país.

Consideram ainda que, se a provinha fosse elaborada levando em conta as particularidades de cada aluno, escola ou região e, se contemplasse todas as disciplinas e não somente Língua Portuguesa e Matemática, poderia ser um instrumento mais útil. Mas como a avaliação é feita de forma padronizada e de forma objetiva fornecendo um resultado quantitativo, não veem como possa contribuir no planejamento escolar.

Quando discorrem sobre os resultados de forma quantitativa, as professoras salientam que avaliar por quanto acertos o aluno obteve é uma forma de classificar os alunos e esse não é o objetivo da escola, já que a escola busca a qualidade do aprendizado e não a quantidade.

[...]é uma prova que já vem pronta é só o aluno marcar a opção certa e depois na correção contar os acertos e isso pra mim é classificar. Aqueles que já estão em nível mais elevado de alfabetização se sobressaem aos demais, na escola não avaliamos o quanto os alunos sabem, mas sim o que eles sabem (PA1). 
Sobre a possibilidade de utilizar os resultados no planejamento escolar e do

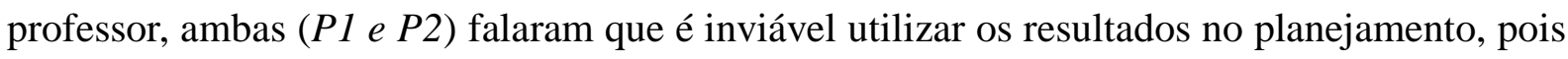
a veem como uma avaliação tradicional que avalia todos de forma igual e não acham justo avaliar alunos em diferentes fazes da mesma forma. Ainda colocaram o fato de a Provinha tentar igualar todos os alunos, não levando em conta o contexto socioeconômico e cultural de cada aluno e, por esse motivo, não levam em conta a Provinha Brasil no planejamento escolar. A professora que aqui identificaremos como $P 2$ ainda ressaltou o seguinte:

Nos últimos tempos muito tem se falado em inclusão, não só a inclusão de alunos
com deficiências, mas, de todos os alunos. Falamos também em respeitar as
especificidades de cada criança ou lugar onde ela vive, e ai aplicamos uma prova
igual para todos e dizemos que estamos avaliando o nível de alfabetização das
crianças. Aí pergunto: como estamos respeitando as especificidades do lugar e da
criança, se aplicamos a mesma prova para por exemplo; crianças que moram na
cidade e as que morram no interior, como é nosso caso? Quando pensamos além de
nossa escola e as diferenças que existem entre regióes e a prova é a mesma, como
estamos respeitando a questão das especificidades e da inclusão? (PA2)

É possível perceber o descontentamento das professoras com a possível utilização dos resultados em suas práticas, pois vivemos em uma sociedade que apresenta diferenças culturais na questão da leitura, em que algumas crianças tem seu primeiro contato com os livros e com a leitura na sala de aula, então avaliar o que a criança aprendeu de acordo com algum gênero literário promove uma classificação desnecessária dentro da escola.

Sobre as avaliações em sala de aula, as professoras concordam que as avaliações feitas pela professora, como parte de seu fazer pedagógico, ajuda muito, mais que uma avaliação feita por alguém de fora que não leva em conta as particularidades e a diversidade dos alunos. Nas palavras das mesmas a forma de avaliar que está contemplada no planejamento escolar é contínua, cumulativa e formativa, e que há casos em que se faz necessário uma recuperação para os alunos que apresentam dificuldades e essa recuperação é feita em paralelo.

Ao falar da recuperação em paralelo a escola atende o que está disposto na LDB 9394/96 no Artigo 12 inciso V, e no Artigo 13 inciso IV, que prevê a recuperação dos alunos com menor rendimento. $\mathrm{E}$ as professoras entrevistadas entendem que essa prática é necessária para a evolução da aprendizagem doa alunos.

As professoras, participantes desta pesquisa, partem do cotidiano dos alunos do concreto, para depois apresentarem novos tipos de leitura. Ao serem questionadas sobre como elas veem a avaliação a resposta foi unanime "como se estivesse alguém de fora me olhando, olhando meu trabalho em sala de aula, cuidando como estou dando aula". As professoras 
entendem que os resultados obtidos pela Provinha Brasil não são utilizados para compor o IDEB da escola, mas mesmo assim não gostaria que seus alunos ficassem para traz dos demais. Ainda comentaram que fazem da Provinha Brasil uma espécie de treino para a ANA, e que a ANA seria mais um treino para a Prova Brasil, já que a ANA e a Prova Brasil são utilizadas para compor o IDEB da escola.

Como Provinha Brasil é vista pelas professoras como treino para as demais, notase que há uma preocupação, em que os alunos, ao chegarem ao $5^{\circ}$ Ano não apresentem dificuldades nos conteúdos cobrados pela prova Brasil, já que essa sim, compõe o IDEB da escola.

Na minha opinião essa avaliação vem de forma engessada apenas nos diz que para o aluno ou a turma ser considerada boa, ou que está no nível considerado bom, tem que atingir a pontuação que for considerada na avaliação. Mas, mesmo assim não queremos que nossos alunos fiquem para trás ou sejam considerados em um nível inferior de aprendizado (P3).

Podemos notar que as professoras entrevistadas para essa pesquisa conhecem e entendem o porquê são feitas essas avaliações com os alunos. Mas como ficou evidente nas respostas, os resultados não são utilizados no planejamento, as professoras entendem que as particularidades de seus alunos e as diferenças apresentadas em sala de aula, precisam ser respeitadas.

As professoras entrevistadas para essa pesquisa também consideram inviável a utilização da Provinha e seus resultados no planejamento, já que essa avaliação não leva em conta as particularidades de cada aluno e escola. Consideram também que a avaliação é uma forma de controle sobre o que é ensinado e ao propor que se utilize os resultados dessa avaliação em sala de aula, pode haver um redimensionamento do que será ensinado visando atingir melhores resultados.

Faz-se necessário um esclarecimento, quando as professoras falam em respeitar os ritmos de aprendizado, além de estarem falando da necessidade de cada aluno e da forma com ele aprende, estão colocando a preocupação com a idade dos alunos, já que nas turmas avaliadas pela provinha, ou seja o $2^{\circ}$ Ano, ainda tem alunos com 06 anos de idade, somente esse ano a escola adotou o Corte Etário ${ }^{4}$ para as matriculas do $1^{\circ}$ ano.

A o se propor que a avaliação da alfabetização seja padronizada, ou seja, igual para todos, desprezando as diferenças culturais, sociais e econômicas, pressupõe uma ação

\footnotetext{
${ }^{4}$ De acordo com o Art. $2^{\circ}$ da Resolução do CNE/CEB No 1 de 14 de janeiro de 2010: Para o ingresso no primeiro ano do Ensino Fundamental, a criança deverá ter 6 (seis) anos de idade completos até o dia 31 de março do ano em que ocorrer a matrícula. Disponível em portal.mec.gov.br/. Acesso em 13 ago. 2017
} 
educativa que não considera a singularidade de cada aluno, descartando os diferentes caminhos trilhados por professores e alunos para que a alfabetização ocorra de fato. Despreza o fato de que cada aluno tem um tempo e uma forma de aprender, a avaliação deve propor que as particularidades sejam respeitas e não ser usada com a intenção de igualar os saberes.

\section{CONCLUSÃO}

As avaliações em larga escala incorporadas pelas reformas educacionais na década de 1990, afetam o cotidiano escolar, o currículo e o trabalho docente, pois, culpabilizan o professor pelos resultados obtidos pelos alunos. A gestão escolar passa a ser uma gestão por resultados, dessa forma o currículo passa a servir de regulador do estado vinculando o rendimento do aluno a um bônus financeiro.

A Provinha Brasil, objeto de estudo dessa pesquisa, como está disposta hoje, serve para que as escolas prestem conta sobre o dinheiro aplicado pelo Banco Mundial na educação brasileira, estimulando o rankeamento entre as escolas em busca de um índice considerado ideal para a educação. Quanto a utilização dos resultados da Provinha Brasil como diagnóstico de planejamento, os estudos apontam para um engessamento do currículo, levando as escolas a direcionar o que será ensinado aos alunos para obter o resultado considerado adequado nessas avaliações.

Diante dos estudos para essa pesquisa conclui que a Provinha Brasil, não pode servir como diagnóstico de planejamento, pois não contempla todas as áreas do conhecimento e na tentativa de igualar os saberes, desconsidera a heterogeneidade dos sujeitos que compõe a escola nos dias de hoje.

\section{REFERÊNCIAS BIBLIOGRÁFICAS}

AVALIAÇÃO DE SISTEMAS EDUCACIONAIS NO BRASIL. A avaliação da aprendizagem escolar na educação básica frente à crescente centralidade das avaliações externas. Disponível em: 〈http://www.sbec.org.br/evt2012/trab55.pdf $>$. Acesso em: 06 jun. 2017.

BONAMINO, Alicia; SOUSA, Sandra Záquia. Três gerações de avaliação da educação básica no Brasil: interfaces com o currículo da/na escola. Educação e Pesquisa, São Paulo, v. 38, n. 2, p. 373-388, abr./jun, 2012.

BORDIN, Tamara Maria. Influências das políticas educacionais internacionais no currículo: Algumas Incursões. SABERES, Natal - RN, v. 1, n. 11, Fev. 2015, 78-93. Disponível em <

https://periodicos.ufrn.br/saberes/article/download/6526/5197> Acesso em:10 jun. 2017.

BRASIL. Inep, Ministério da Educação. Provinha Brasil: passo a passo (primeiro semestre). Brasília: Inep e Ministério da Educação, 2008a. 
BRASIL. Inep, Ministério da Educação. Provinha Brasil: passo a passo (primeiro semestre). Brasília: Inep e Ministério da Educação, 2008b.

BRASIL. INEP. Portaria Normativa $\mathbf{n}^{\mathbf{0}}$ 10, de 24 de abril de 2007. Disponível em: http://download.inep.gov.br/educacao_basica/provinha_brasil/legislacao/2007/ provinha_brasil_portaria_normativa_n10_24_abril_2007.pdf. Acesso 08 ago. de 2017.

BRASIL. INEP. Provinha Brasil. Disponível em: 〈http://inep.gov.br/provinha-brasil〉. Acesso em: 23 mai. 2017.

BRASIL.INEP. Sobre a ANA. Disponível em: <http://portal.inep.gov.br/educacaobasica/saeb/sobre-a-ana>. Acesso em: 25 mai. 2017.

BRASIL. Lei de Diretrizes e Bases da Educação Nacional, Lei n. 9.394, de 24 de dezembro de 1996

BRASIL. Ministério da Educação. Secretaria de Educação Básica. Secretaria de Educação Continuada, Alfabetização, Diversidade e Inclusão. Conselho Nacional da Educação. Diretrizes Curriculares Nacionais Gerais da Educação Básica/ Ministério da Educação. Secretária de Educação Básica. Diretoria de Currículos e Educação Integral. - Brasília: MEC, SEB, DICEI, 2013.

BRASIL. [Plano Nacional de Educação (PNE)]. Plano Nacional de Educação 2014-2024 [recurso eletrônico]: Lei no 13.005 , de 25 de junho de 2014, que aprova o Plano Nacional de Educação (PNE) e dá outras providências. - Brasília: Câmara dos Deputados, Edições Câmara, 2014. 86 p. - (Série legislação; n. 125)

CARIA, Neide Pena. OLIVEIRA, Sandra Maria da Silva Sales. Avaliação em Larga Escala e a Gestão da Qualidade da Educação, Revista de Ciências Humanas - Educação | FW | v. 16 | n. 26 | p. 22-40 | Jul. 2015.

CASEIRO, Cintia Camargo Furquim. GEBRAN, Raimunda Abou. Avaliação formativa: concepção, práticas e dificuldades, Nuances: estudos sobre Educação. Presidente Prudente, SP, ano XIV, v. 15, n. 16, p. 141-161, jan./dez. 2008.

CHIRINÉA, Andréia Melanda. O Índice de Desenvolvimento da Educação Básica (IDEB) e as dimensões associadas à qualidade da educação na escola pública municipal / Andréia Melanda Chirinéa. - Marília, 2010, Dissertação (Mestrado em Educação) - Faculdade de Filosofia e Ciências, Universidade Estadual Paulista, 2010.

COTTA, Tereza Cristina. Avaliação educacional e políticas públicas: a experiência do Sistema Nacional de Avaliação da Educação Básica (Saeb). Revista do Serviço Público, Brasília, v. 52, n. 4, p. 89-110, out./dez. 2001. Disponível em: <http://repositorio.enap.gov.br/handle/1/2067>. Acesso em: 01 jun. 2017.

ESTEBAN, Maria Teresa. A negação do direito à diferença no cotidiano escolar Avaliação. Revista da Avaliação da Educação Superior, vol. 19, núm. 2, julio, 2014, pp. 463-486 Universidade de Sorocaba Sorocaba, Brasil. 
ESTEBAN, Maria Teresa. Considerações sobre a política de avaliação da alfabetização: pensando a partir do cotidiano escolar. Revista Brasileira de Educação v. 17 n. 51 set.-dez. 2012.

ESTEBAN, Maria Teresa. WOLF, Célia Claudia. Um olhar para a alfabetização a partir dos exames nacionais, Revista de Estudios e Investigación en Psicología y Educación, eI SSN: 2386-7418, Vol. Extr., No. 10. DOI: 10.17979/reipe.2015.

HORTA NETO, João Luiz. Um olhar retrospectivo sobre a avaliação externa no Brasil: das primeiras medições em educação até o SAEB de 2005, Revista Iberoamericana de Educación (ISSN: 1681-5653), n. ${ }^{\circ}$ 42/5 - 25 de abril de 2007.

LOPES, Ângela Tenilly Ribeiro. A importância do planejamento para o sucesso escolar. / Ângela Tenilly Ribeiro Lopes. Redenção, 2014. 60 f.; 30 cm. Monografia do curso de Especialização em Gestão Pública Municipal da Universidade da Integração Internacional da Lusofonia Afro-brasileira - UNILAB.

LUCKESI, Cipriano Carlos. Avaliação da aprendizagem componente do ato pedagógico/ Cipriano Carlos Luckesi - 1. ed. - São Paulo: Cortez, 2011.

MESQUITA, M. De F, M.; COELHO, M. H. M. Breve trajetória histórico pedagógica do planejamento de ensino e da avaliação da aprendizagem. Dialogia, São Paulo, v. 7, n. 2, p. $163-175,2008$

PERONI, V. M. V. Avaliação institucional em tempos de redefinições no papel do Estado. Revista Brasileira de Administração da Educação, 2009.

PORTAL MEC. Prova Brasil-apresentação. Disponível em: <http://portal.mec.gov.br/provabrasil >. Acesso em: 08 mar. 2017.

RONCA, Antônio Carlos Caruso. Avaliação da educação básica: Seus limites e possibilidades. Revista Retratos da Escola, Brasília, v. 7, n. 12, p. 77-86, jan./jun. 2013. Disponível em: <http//www.esforce.org.br> Acesso em:10 jun. 2017

SILVA, Erika Radespiel Fernandes da. Provinha Brasil: o instrumento, perspectivas e análise. Brasília/DF, Universidade de Brasília/Faculdade de Educação (Trabalho de Conclusão de Curso - Graduação), 2012.

SOARES, Magda. Letramento: um tema em três gêneros / Magda Soares. - 3. Ed - Belo Horizonte: Autentica Editora, 2009. (p. 07-49)

SOUSA, Sandra Zákia. Concepções de qualidade da educação forjadas por meio de avaliações em larga escala. Avaliação. Campinas, Sorocaba SP, v. 19, n. 12, p. 407-420, jul. 2014.

SOUSA, Sandra Zákia. Possíveis impactos das políticas de avaliação no currículo escolar. Cadernos de Pesquisa, n. 119, p. 175-190, julho/ 2003.

SOUZA, lanara Guimarães de. Avaliação de políticas educacionais: contexto e conceitos em busca da avaliação pública. In Avaliação educacional: desatando e reatando nós / Jose Albertino Carvalho Lordelo, Maria Virginia Dazzani (organizadores). - Salvador: 
EDUFBA,2009.

WERLE, Flavia Obino Corrêa. Políticas de avaliação em larga escala na educação básica: do controle de resultados à intervenção nos processos de operacionalização do ensino, Ensaio: aval. pol. públ. Educ., Rio de Janeiro, v. 19, n. 73, p. 769-792, out./dez. 2011.

Wiebusch, Eloisa Maria. Avaliação externa: um caminho para a busca da qualidade da educação / Eloisa Maria Wiebusch. - Porto Alegre, 2011, Dissertação (Mestrado em Educação) Faculdade de Educação, PUCRS. 